\title{
Quantitative Microstructural Characterization of Thick Aluminum Plates Heavily Deformed Using Equal Channel Angular Extrusion
}

Mishin, Oleg; Segal, V.M.; Ferrasse, S.

Published in:

Metallurgical and Materials Transactions A: Physical Metallurgy and Materials Science

Link to article, DOI:

$10.1007 / \mathrm{s} 11661-012-1287-1$

Publication date:

2012

Document Version

Publisher's PDF, also known as Version of record

Link back to DTU Orbit

Citation (APA):

Mishin, O., Segal, V. M., \& Ferrasse, S. (2012). Quantitative Microstructural Characterization of Thick Aluminum Plates Heavily Deformed Using Equal Channel Angular Extrusion. Metallurgical and Materials Transactions A: Physical Metallurgy and Materials Science, 43, 4767-4776. https://doi.org/10.1007/s11661-012-1287-1

\section{General rights}

Copyright and moral rights for the publications made accessible in the public portal are retained by the authors and/or other copyright owners and it is a condition of accessing publications that users recognise and abide by the legal requirements associated with these rights.

- Users may download and print one copy of any publication from the public portal for the purpose of private study or research.

- You may not further distribute the material or use it for any profit-making activity or commercial gain

- You may freely distribute the URL identifying the publication in the public portal 


\title{
Quantitative Microstructural Characterization of Thick Aluminum Plates Heavily Deformed Using Equal Channel Angular Extrusion
}

\author{
O.V. MISHIN, V.M. SEGAL, and S. FERRASSE
}

A detailed quantitative analysis of the microstructure has been performed in three orthogonal planes of 15-mm-thick aluminum plates heavily deformed via two equal channel angular extrusion (ECAE) routes. One route was a conventional route A with no rotation between passes. Another route involved sequential $90 \mathrm{deg}$ rotations about the normal direction (ND) between passes. The microstructure in the center of these plates, and especially the extent of microstructural heterogeneity, has been characterized quantitatively and compared with that in bar samples extruded via either route $\mathrm{A}$ or route $\mathrm{Bc}$ with 90 deg rotations about the longitudinal axis. Statistically robust data were obtained in this work using gallium enhanced microscopy and EBSD mapping of large sample areas. For the plate processed using route A, the fraction of high-angle boundaries was found to strongly depend on the inspection plane, being smallest in the plane perpendicular to the ND (plane $Z$ ), where the largest subgrain size and most profound microstructural heterogeneities were also revealed. In comparison, the plate extruded with 90 deg rotations about the ND was less heterogeneous and contained smaller subgrains in plane $Z$. Comparing the plate and bar samples, the most refined and least heterogeneous microstructure was observed in the route $\mathrm{Bc}$ bar sample. The differences in the microstructure are reflected in the hardness data; the hardness is lowest after ECAE via route A and greatest in the bar sample processed using route Bc.

DOI: $10.1007 / \mathrm{s} 11661-012-1287-1$

(C) The Minerals, Metals \& Materials Society and ASM International 2012

\section{INTRODUCTION}

THE current interest in materials processed by heavy plastic deformation is largely stimulated by their unusual properties due to the presence of nanocrystalline and submicrocrystalline structures. ${ }^{[1]}$ A number of new processing techniques has been proposed for structural refinement by application of multiple deformation passes. ${ }^{[2]}$ One technique that has received particular attention is equal channel angular extrusion (ECAE),${ }^{[1-6]}$ in which a billet is repeatedly extruded through a die with two equal intersecting channels.

Despite the fact that ECAE is an effective processing technique for attaining very high strains in bulk samples, until now it has mainly been used only on the laboratory scale, mostly for producing and studying comparatively small bar and rod samples. A promising development of the ECAE technique is its recent adaption for processing of plate samples. ${ }^{[3,6-10]}$ Large plates obtained by ECAE can be either used directly for

O.V. MISHIN, Senior Scientist, formerly with Materials Research Department, Risø National Laboratory for Sustainable Energy, Roskilde, Denmark, is now with the Danish-Chinese Center for Nanometals, DTU Wind Energy, Technical University of Denmark, 4000 Roskilde, Denmark. Contact e-mail: olmi@dtu.dk V.M. SEGAL, Chief Technology Officer, is with Engineered Performance Materials, Whitmore Lake, MI 48198. S. FERRASSE, Principal Engineer, is with Honeywell International, Morristown, NJ 07962.

Manuscript submitted December 16, 2011

Article published online July 6, 2012 various applications or can be subjected to additional forming operations, e.g., rolling, for which the plate geometry is particularly suitable. It is obvious that in order to obtain long strips or sheets from ECAEprocessed plates by rolling, the thickness of these plates must be sufficiently large. Thus, processing of thick ECAE plates is expected to be especially important for potential industrial applications.

It is significant that in addition to deformation routes previously used for bar and rod samples, processing of plates enables unique routes where the sample is rotated 90 deg about the plate normal. Even though plate samples are certainly more attractive in terms of industrial processing than bars and rods, there have only been very few experimental studies of ECAE plates. Moreover, in some of these publications, the extent of microstructural characterization was limited to the measurement of the average boundary spacing and to considering general morphological characteristics of the observed deformation structures ${ }^{[8]}$ Boundary misorientations have been measured in several studies of ECAE plates. ${ }^{[11,12]}$ However, since these measurements were conducted only in one plane, a complete description of the boundary network formed during ECAE deformation of plates has not been provided.

The aim of the current work is twofold. First, this study is aimed at conducting a detailed quantitative analysis of the microstructure in three orthogonal planes in thick aluminum plates heavily deformed via two ECAE routes. One route is a conventional route A with no sample 
rotation between passes. The other route used in this work involves 90 deg rotations about the normal direction, and it is unique for ECAE of plate samples. For these plates, statistically sound quantitative information both for average parameters of the microstructure and for the microstructural heterogeneity is presented. The second aim of the study is to compare the microstructure, and especially the extent of microstructural heterogeneity, of these plates with the characteristics reported for bar and rod samples. To enable a direct comparison between plate and bar samples, an analysis of the microstructure in ECAE-processed bars has also been performed as part of the current work. The microstructural analysis is complemented by microhardness measurements.

\section{EXPERIMENTAL}

Aluminum AA1050 (99.5 pct purity) with an average recrystallized grain size of $\sim 50 \mu \mathrm{m}$ was used to produce ECAE plate and bar samples. Two plate samples with dimensions of $15 \times 75 \times 75 \mathrm{~mm}^{3}$ were extruded using a $140 \mathrm{t}$ hydraulic press at a speed of $1 \mathrm{~mm} / \mathrm{s}$. A die with a sharp outer corner and a 90 deg angle between channels was used for room-temperature processing (Figure 1). Nearly frictionless deformation, with localized uniform simple shear $\gamma=2$ at an angle of $45 \mathrm{deg}$ to the extrusion direction, was provided by use of a sliding floor ${ }^{[6,9,10]}$ and an antiseize lubricant. One plate (sample PA) was deformed with no rotation; the other plate (sample PB) was extruded with sequential 90 deg clockwise rotations about the plate normal direction (ND in Figure 1) after each pass. For each plate, eight ECAE passes were performed. In addition, two bar samples, $15 \times 15 \times 75 \mathrm{~mm}^{3}$, were processed also by eight passes either via route $\mathrm{A}$ (sample $\mathrm{A}$ ) or via route $\mathrm{Bc}$ (sample $\mathrm{Bc}$ ). The latter route involved sequential 90 deg clockwise rotations about the extrusion direction (ED in Figure 1). The same overall die design, process speed, and nearly frictionless conditions were used for extruding the bars.

After deformation, Vickers microhardness measurements were made on a polished surface in plane $Y$ (Figure 1) using a load of $200 \mathrm{~g}$ with 15 seconds of dwell time. The measurements were made along two lines in the center part of each sample. The distance between each measurement was $0.8 \mathrm{~mm}$. In total, at least 30 measurements were made for each sample.

Microstructural characterization was performed in a center part of the deformed samples in sections

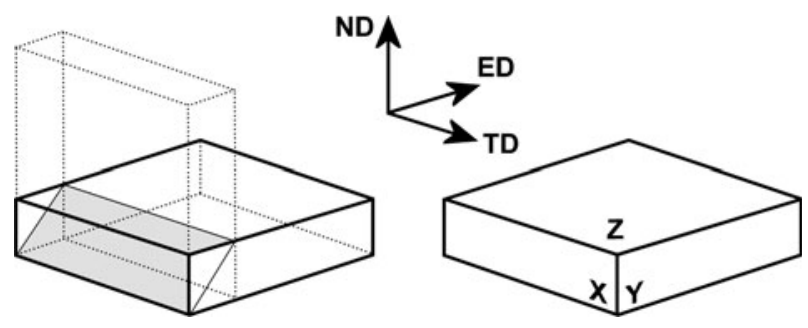

Fig. 1-Schematic of plate processing and designations of the inspected planes $(X, Y$, and $Z)$. The shear plane is shown in gray. ND, $\mathrm{ED}$, and TD correspond to the normal, extrusion, and transverse directions, respectively. corresponding to three orthogonal planes, $X, Y$, and $Z$ (Figure 1). The sample preparation included mechanical and electrochemical polishing. The sections were inspected using the electron backscatter diffraction (EBSD) technique in a field-emission gun scanning electron microscope Zeiss Supra 35 (Carl Zeiss, Oberkochen, Germany) equipped with a Channel 5 system and a Nordlys detector (Oxford Instruments, Oxfordshire, U.K.). The EBSD measurements were conducted at $15 \mathrm{kV}$ with the specimen tilted to $70 \mathrm{deg}$. Taking into account that the tilt results in different spatial resolutions in the directions either parallel $\left(\Lambda_{\|}\right)$or perpendicular $\left(\Lambda_{\perp}\right)$ to the tilt axis, where $\Lambda_{\perp} \approx 3 \Lambda_{\|,}$, ${ }^{13]}$ specimens with the strongest directionality of the microstructure were oriented so that the direction of subgrain elongation in the inspected plane was nearly perpendicular to the tilt axis.

An initial assessment of the extent of heterogeneity in the different samples was carried out using a number of EBSD maps collected with large step sizes between 0.7 and $1.5 \mu \mathrm{m}$. A quantitative analysis of microstructural heterogeneity and boundary populations was then conducted by EBSD using a smaller step size, $70 \mathrm{~nm}$, and covering a total area of 30,000 to $50,000 \mu \mathrm{m}^{2}$ in each sample, except for the bar A sample, for which an area of only $10,000 \mu \mathrm{m}^{2}$ was analyzed. Since the structural parameters and hardness in this sample appeared almost identical to those in sample PA, further characterization of the route A bar sample was considered to be unnecessary. The data collected for the plate sample PA deformed via route $\mathrm{A}$ in our experiment are regarded, therefore, as being representative of the microstructure of the bar sample processed via the same route. Finally, several small regions in each sample were mapped with a step size of $40 \mathrm{~nm}$ to reveal fine details of the microstructure.

Because of the limited angular resolution of the EBSD technique, fractions of different boundary types were calculated considering only misorientations $>2 \mathrm{deg}$. The fact that boundaries below $2 \mathrm{deg}$ are not confidently identified in EBSD maps can be critical for accurate measurements of the subgrain size from the EBSD data. To detect subgrain boundaries with even very low misorientations, gallium-enhanced microscopy $(\mathrm{GEM})^{[14]}$ was also applied in the current experiment. The GEM technique uses atomic-number contrast from gallium decorated boundaries in aluminum, thus making them observable using a backscattered-electron (BSE) imaging mode. It has been shown that this technique is able to detect dislocation boundaries with misorientations even below 1 deg. ${ }^{[1]}$ The GEM approach has previously been successfully applied in the characterization of deformation structures in several investigations of deformed Al-alloys. ${ }^{[15-17]}$

\section{RESULTS}

\section{A. Average Parameters}

Examples of misorientation maps collected from the plate samples using the EBSD technique are shown in Figures 2 and 3 . In sample PA, extended boundaries are 


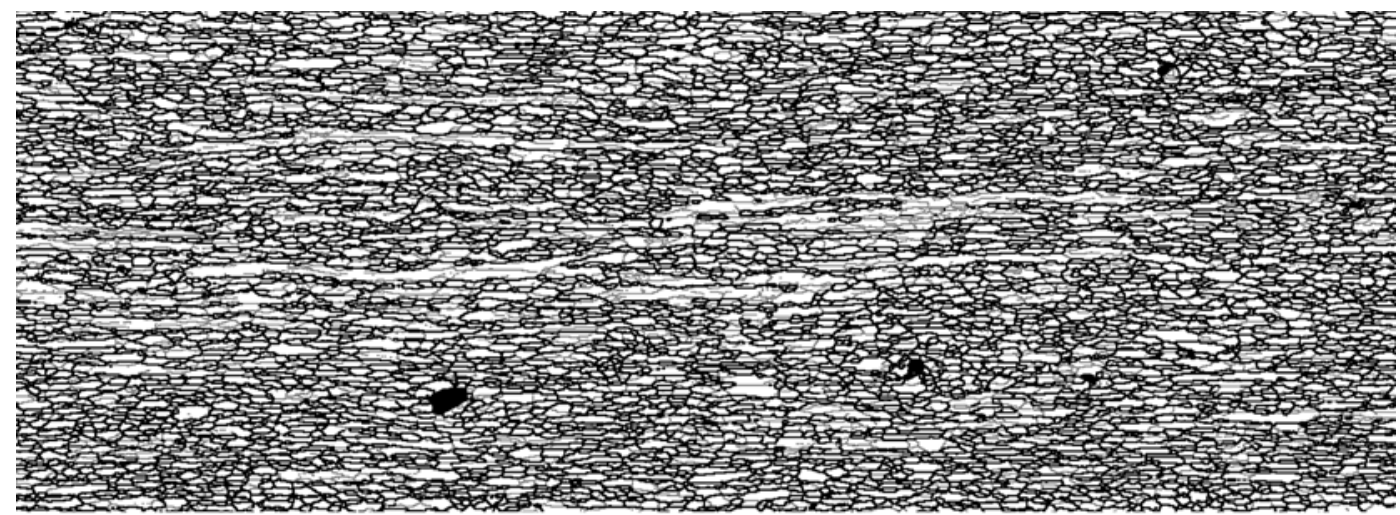

(a)

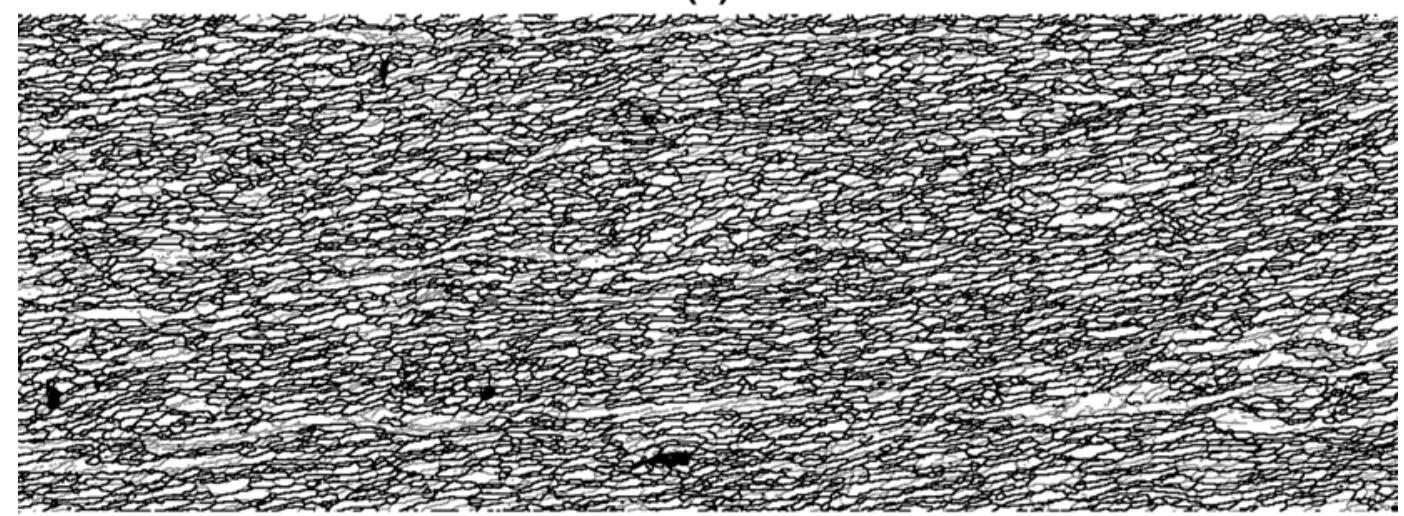

(b)

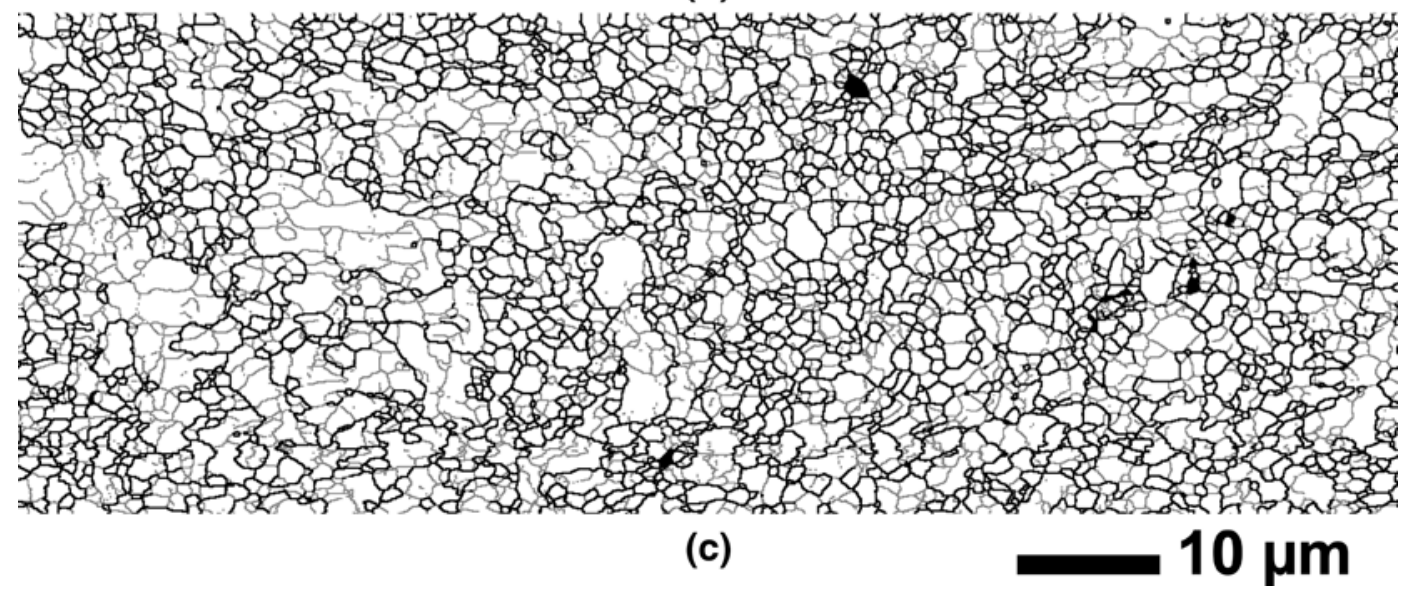

Fig. 2-Misorientation maps illustrating the microstructure in sample PA: $(a)$ plane $X$, $(b)$ plane $Y$, and $(c)$ plane $Z$. The scale bar is parallel to the transverse direction in (a) and to the extrusion direction in $(b, c)$. Thin lines correspond to misorientations between 2 and 15 deg. Bold lines show high-angle ( $>15 \mathrm{deg}$ ) boundaries. Dark regions represent coarse particles present in the microstructure.

aligned along the TD in plane $X$ (Figure 2(a)) and inclined at an angle of 3 to 7 deg to the ED when viewed in plane $Y$ (Figure 2(b)). Planes $X$ and $Y$ in this sample are characterized by a small spacing between high-angle boundaries (HABs) along the ND $(\sim 0.4 \mu \mathrm{m})$, which results in large frequencies of HABs, 73 to $77 \mathrm{pct}$, in these two planes (Figure 4). The microstructure is less refined in plane $Z$ (Figure 2(c)), where the HAB fraction is only $\sim 60$ pct.

The directionality of deformation structures in planes $X$ and $Y$ of sample PB (Figures 3(a) and (b)) is less pronounced than in sample PA. Considering EBSD maps from planes $Z$ of both plates, the microstructure appears more refined in sample PB (compare Figures 2(c) and 3(c)). For this sample, the fractions of $\mathrm{HABs}$ in each of the three inspected planes are very similar, $\sim 70$ pet (Figure 4).

The subgrain size, expressed as the average equivalent circular diameter (ECD), has been calculated from the measured area of subgrains seen in the GEM images (an example is given in Figure 5). In both plates, the mean subgrain size was approximately $0.5 \mu \mathrm{m}$ in planes $X$ and $Y$ (Figure 6). Larger average values, 0.7 to $0.8 \mu \mathrm{m}$, were obtained in plane $Z$. The average subgrain sizes as determined from the GEM images were on average 9 pct smaller than the sizes calculated from EBSD maps 


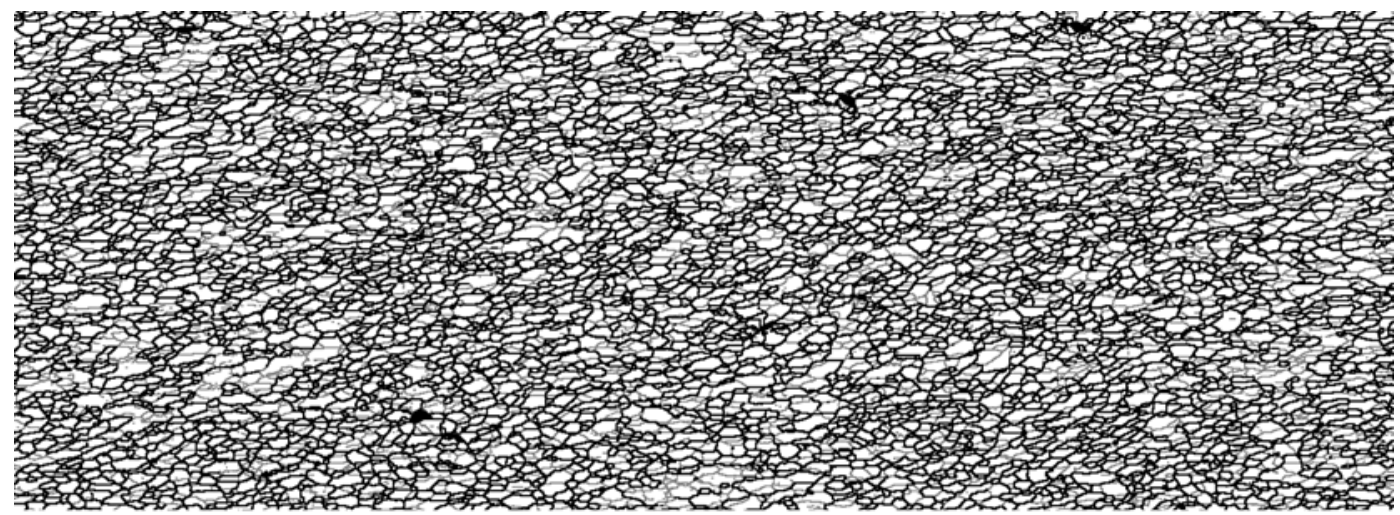

(a)

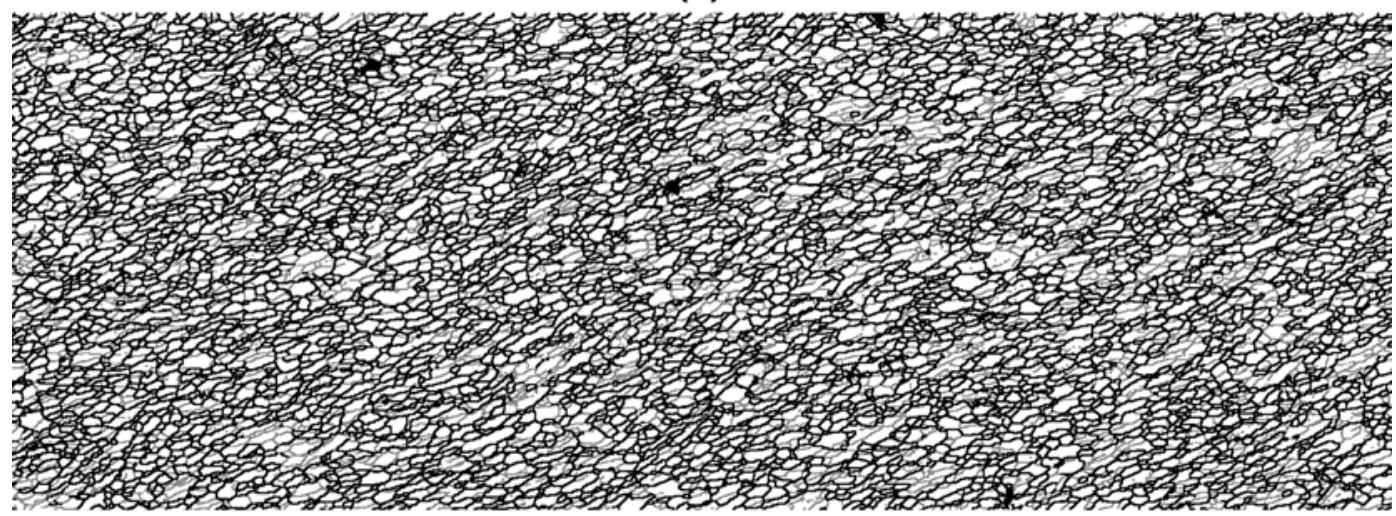

(b)

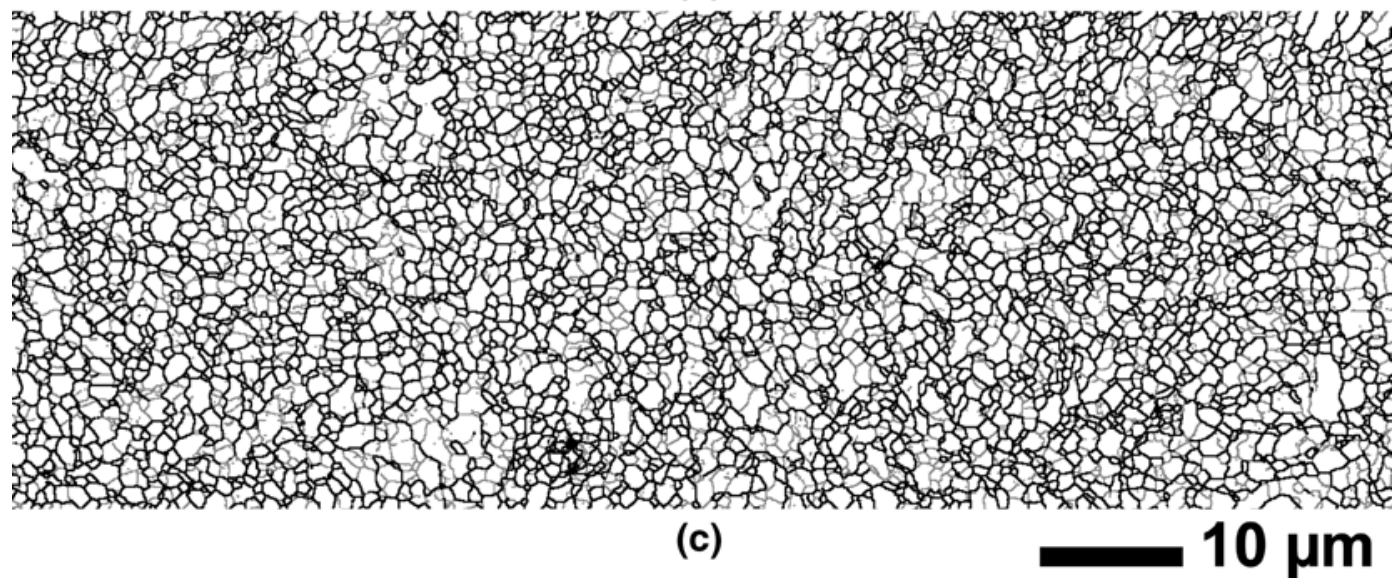

Fig. 3-Misorientation maps illustrating the microstructure in sample PB: $(a)$ plane $X,(b)$ plane $Y$, and $(c)$ plane $Z$. The scale bar is parallel to the transverse direction in (a) and to the extrusion direction in (b,c). Thin lines correspond to misorientations between 2 and 15 deg. Bold lines show high-angle ( $>15 \mathrm{deg}$ ) boundaries. Dark regions represent coarse particles present in the microstructure.

obtained with the finest step size of $40 \mathrm{~nm}$ using a boundary definition angle of $2 \mathrm{deg}$. Thus, in the current experiment, the GEM approach was able to identify more dislocation boundaries than the EBSD analysis.

Compared to the plates, the bar sample $\mathrm{Bc}$ is characterized by smaller values of the average subgrain size in planes $X$ and $Z$ (Figure 6). Similar to sample PB, there are no significant differences in the HAB fraction for the three orthogonal planes of this bar sample (Figure 4).

The results of the microhardness measurements are shown in Figure 7. It is evident that the lowest hardness was obtained in sample PA, whereas the highest average value was recorded for sample Bc.

\section{B. Microstructural Heterogeneity}

The EBSD data indicated that the deformed microstructure of all the samples inspected was not homogeneous. In each investigated sample, well-refined areas subdivided by predominantly HABs were combined with regions containing mostly low-angle misorientations. In planes $X$ and $Y$ of sample PA, such regions appear in the form of bands of various thickness and length 


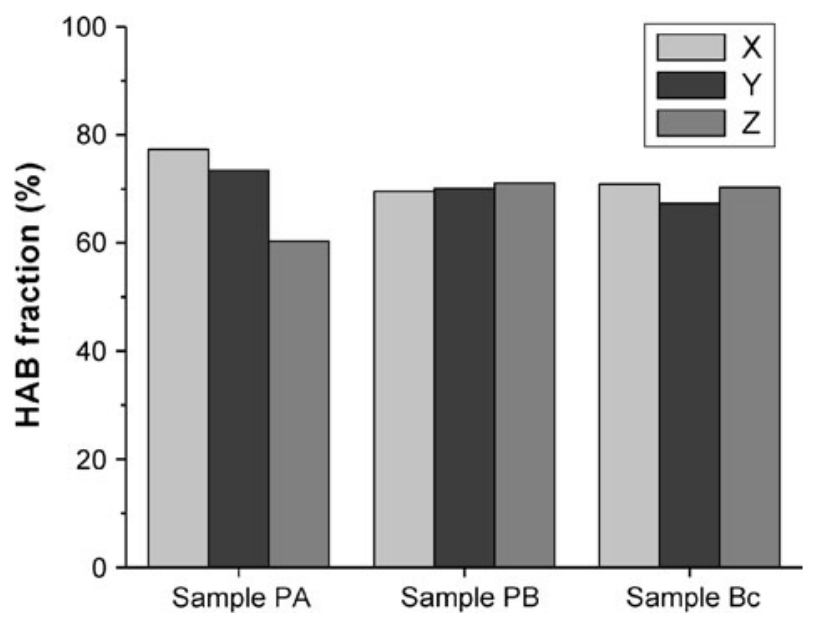

Fig. 4-Fractions of HABs calculated from the EBSD data.

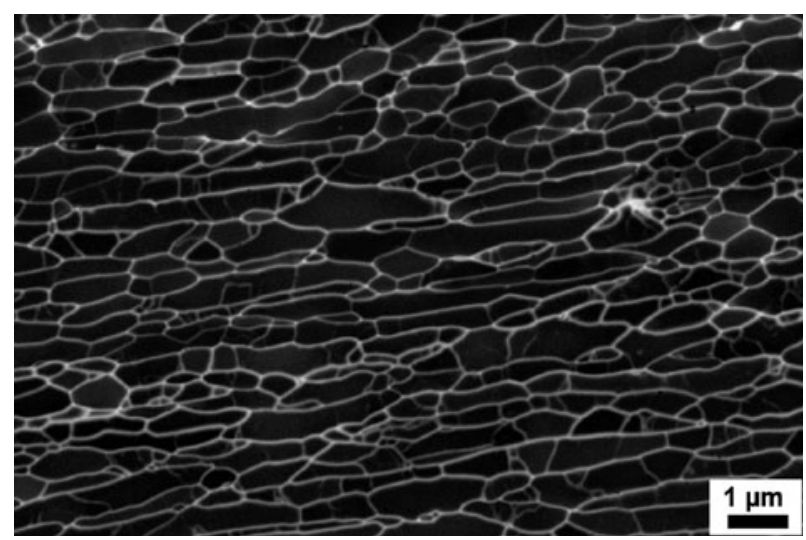

Fig. 5-Example GEM image from plane $Y$ of sample PA. Ga-decorated boundaries are seen as bright features.

(Figures 2(a) and (b)). Regions with predominantly low misorientations were found to occupy large areas in the microstructure observed in plane $Z$ (Figure 2(c)). The heterogeneity is less apparent in sample PB (Figure 3); however, also here regions with substantially different proportions of HABs and LABs were present.

To describe the extent of microstructural heterogeneity in a quantitative manner, area fractions of regions with predominantly either low or high misorientations (low misorientation regions [LMRs] or high misorientation regions [HMRs]) can be calculated from the EBSD data. Following previous work ${ }^{[18-20]}$ this was done in the present experiment by carrying out a "grain reconstruction" process using a misorientation angle of at least 5 deg to define a "grain." Grains with a size greater than some chosen value $\mathrm{A}^{*}$ are considered to be LMRs. The remaining area is defined as consisting of HMRs. The result of such a partitioning for $\mathrm{A}^{*}=2.5 \mu \mathrm{m}^{2}$ is illustrated in Figure 8 , where the LMR and HMR subsets are shown in white and gray, respectively. Note that the large white areas in the figure may comprise several LMRs separated by misorientations $>5 \mathrm{deg}$. The partitioning allows fractions of the different regions to be determined, thus providing a quantitative measure of microstructural heterogeneity.

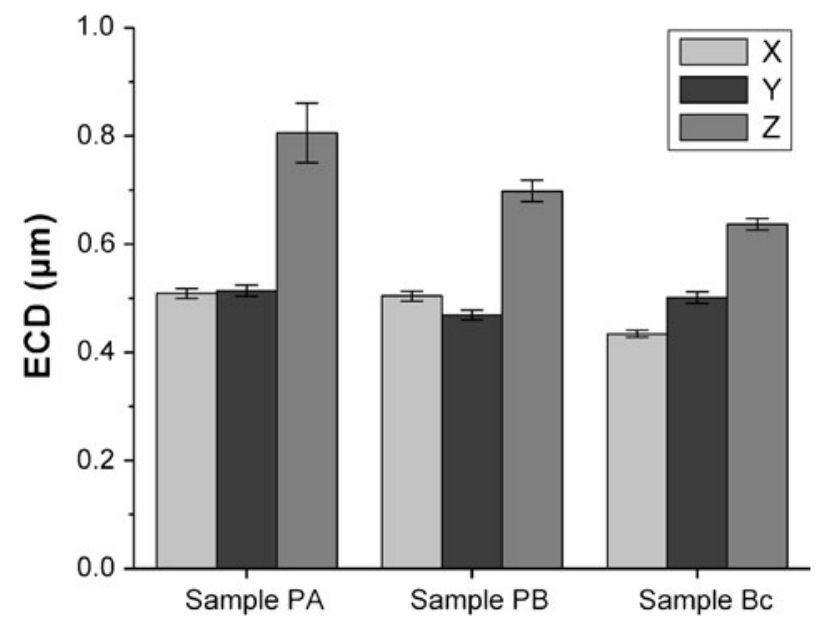

Fig. 6-The ECD of subgrains as measured from GEM images. The error bars correspond to the standard error.

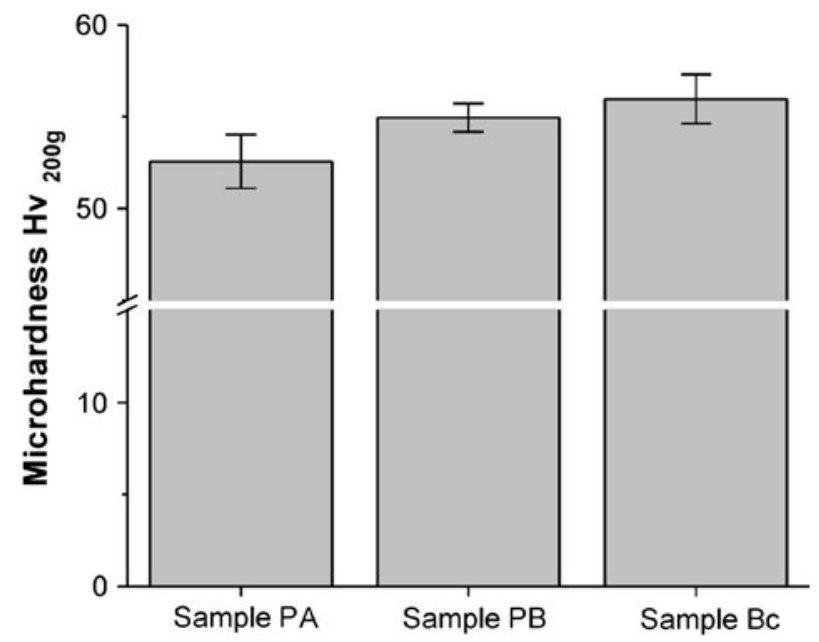

Fig. 7-Vickers hardness data for the ECAE-deformed samples. The error bars correspond to the standard error.

It is clear that for a given critical grain reconstruction misorientation angle, the calculated fractions of LMRs and HMRs may be very sensitive to the choice of $\mathrm{A}^{*}$. As shown in Figure 9, the LMR fraction first decreases very rapidly with increasing $\mathrm{A}^{*}$. At $\mathrm{A}^{*}>2.5 \mu \mathrm{m}^{2}$, the reduction in the LMR fraction slows down. In each sample, the greatest LMR fractions were recorded in plane $Z$, whilst the lowest LMR fractions for different values of $\mathrm{A}^{*}$ were typically found in plane $X$. Comparing the data for all samples as a function of $A^{*}$, LMR fractions were observed to be largest in plane $Z$ of sample PA and lowest in plane $X$ of sample Bc for a wide range of $A^{*}$ (Figure 9).

Since the subgrain size is different in the different planes (Figure 6), it is reasonable to relate $A^{*}$ to the average subgrain size in each inspected plane, defining $\mathrm{A}^{*}$ as an area of a certain number of subgrains within the microstructure. ${ }^{[21]}$ Figure 10 shows LMR fractions calculated for $A^{*}$ defined as an area of 10 average-size subgrains. It is seen that also in this case LMR fractions 


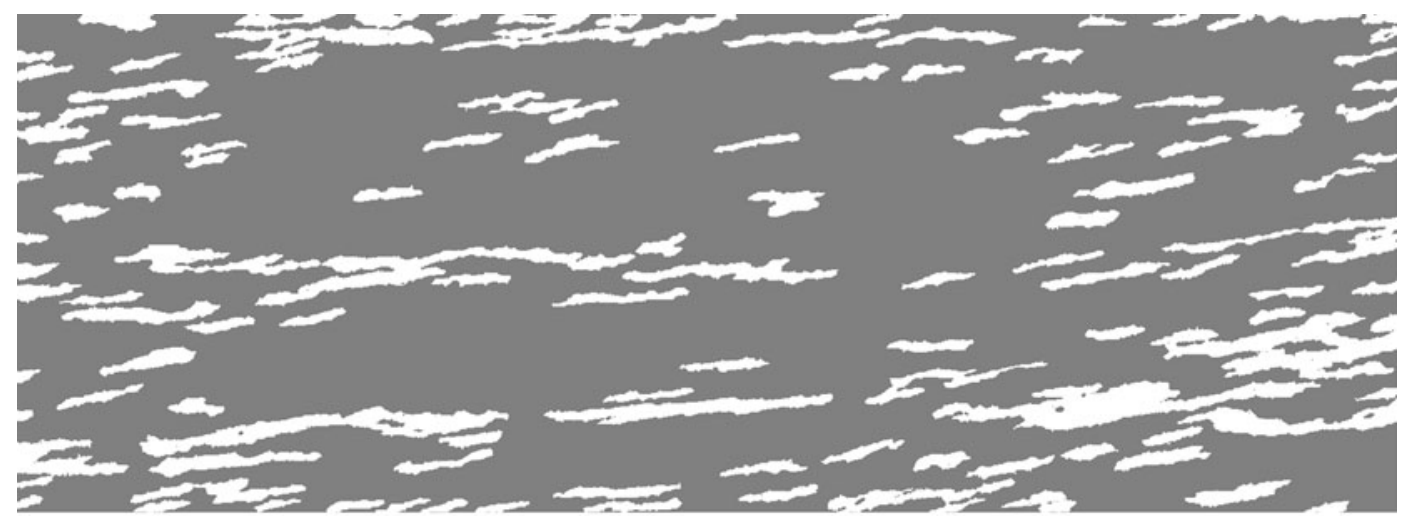

(a)

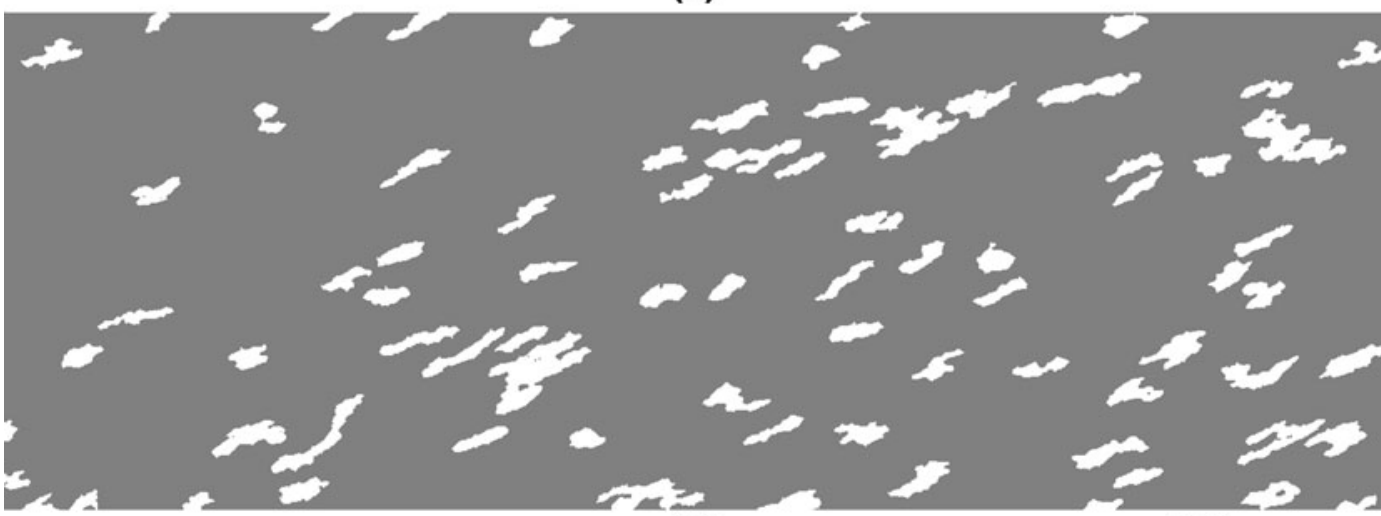

(b)

Fig. 8-EBSD maps from plane $Y$ of the ECAE-processed plates showing the microstructure partitioned into LMR (white) and HMR (gray) subsets at $\mathrm{A}^{*}=2.5 \mu \mathrm{m}^{2}$ : (a) sample PA and $(b)$ sample PB.

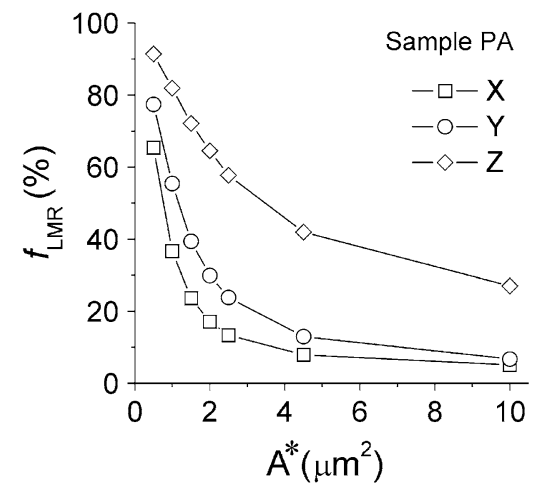

(a)

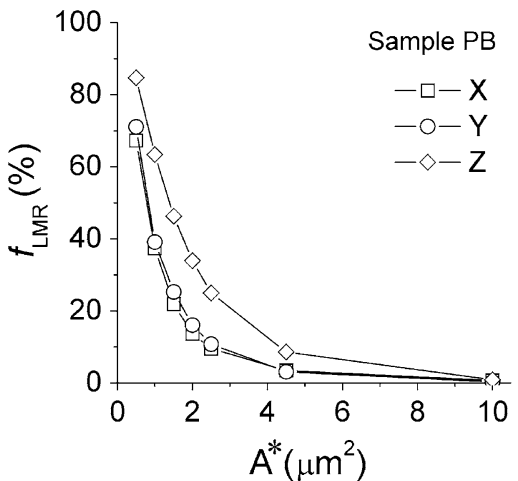

(b)

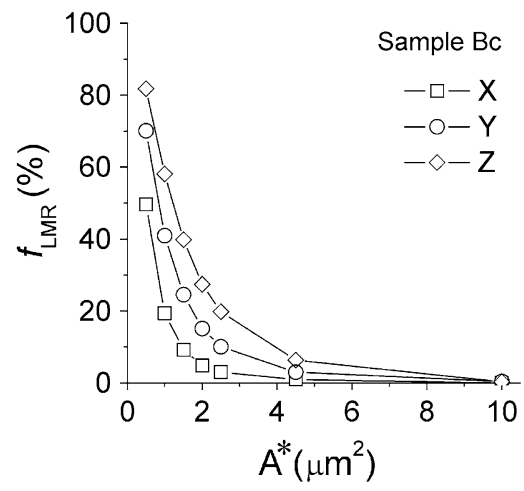

(c)

Fig. 9-Fractions of LMRs calculated for different values of the critical region size $\mathrm{A}^{*}$ : (a) sample PA, (b) sample PB, and (c) bar sample Bc.

are higher in sample PA than in the other inspected samples (Figure 10).

\section{DISCUSSION}

\section{A. Effect of Processing Route on the Microstructure of Plate Samples}

The two routes used for processing of the plate samples resulted in substantial differences both in morphology and in the quantitative parameters describ- ing the deformed microstructures. After several ECAE passes with no plate rotation, highly elongated structures closely inclined to the ED develop in sample PA. This type of structure resembles lamellae in materials heavily deformed by cold rolling ${ }^{[22-24]}$ and, as mentioned previously, is very similar to that observed for bar and rod samples deformed via route A. It has been shown that in such ECAE-processed samples, the inclination of lamellar boundaries generally corresponds to geometric changes in a cubic element during deformation. ${ }^{[25]} \mathrm{A}$ decrease in the boundary spacing with increasing 


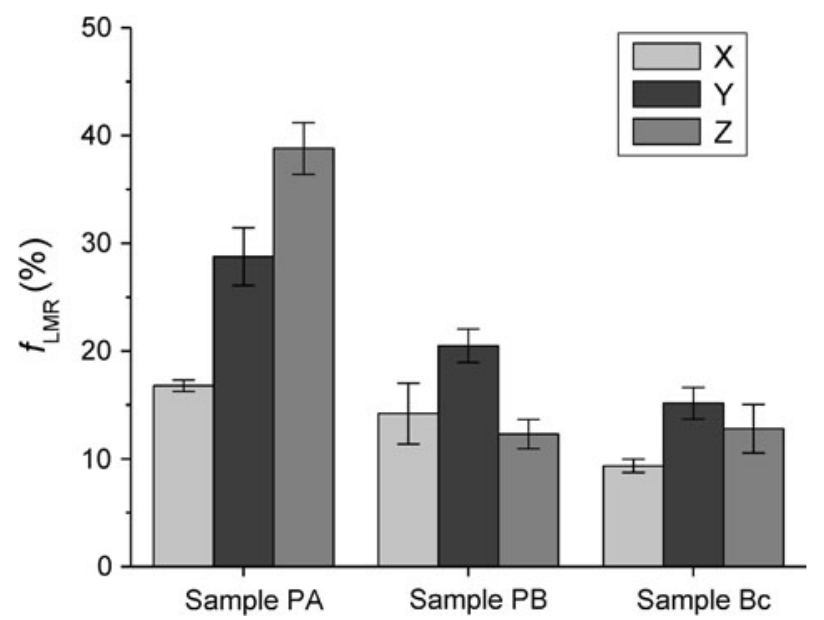

Fig. 10-Fractions of LMRs calculated for $\mathrm{A}^{*}$ defined as an area of 10 average-size subgrains. The error bars correspond to the standard error.

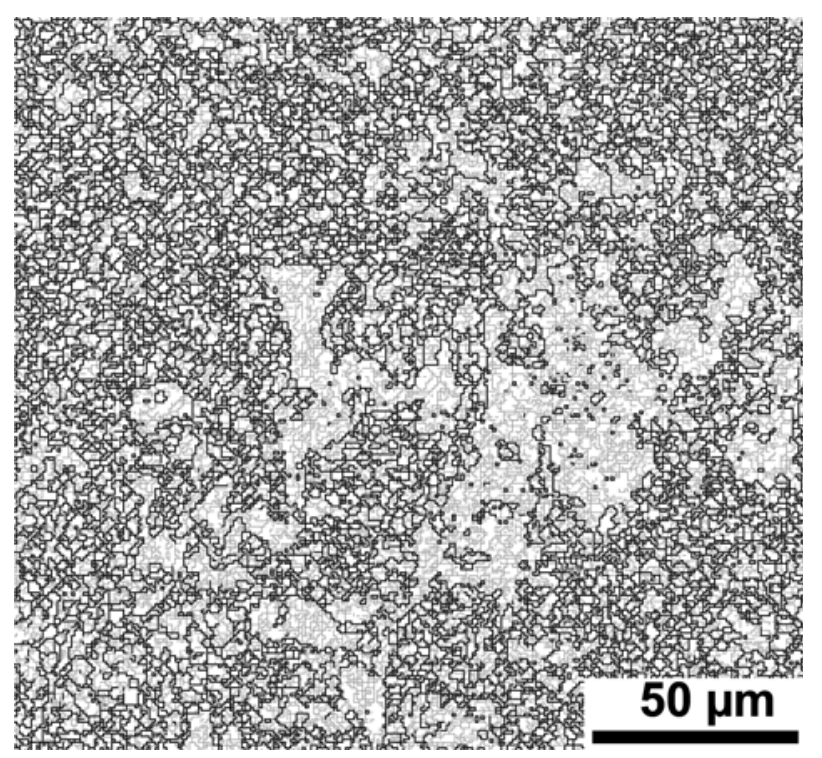

Fig. 11-A large area EBSD map illustrating the scale of heterogeneity in the $Z$ plane of sample PA.

number of passes has been attributed both to decreasing thickness of the existing lamellae and to the development of new lamellar boundaries. ${ }^{[26]}$ After large strains, most of the finely spaced lamellar boundaries are HABs, which explains the very large HAB fractions frequently reported in the $X$ and $Y$ planes after ECAE with no sample rotation. ${ }^{[25-29]}$

The refinement is, however, not uniform even after eight ECAE passes, with predominance of very low misorientations in some regions. Such regions are categorized in the current work as LMRs. In certain locations, LMR bands can reach several microns in thickness. Similar LMR bands have also been observed for bar and rod samples processed via route $A .^{[18-20]} \mathrm{It}$ has been suggested that such broad bands are produced from large original grains that have resisted breaking into highly misoriented volumes during multipass
ECAE. ${ }^{[19]}$ Similar to previous findings made in copper deformed via route $\mathrm{A},{ }^{[19]}$ crystallographic orientations of LMRs in sample PA corresponded to pronounced intensity maxima near the $\mathrm{B}_{\theta} / \overline{\mathrm{B}}_{\theta}$ components of the ECAE texture, ${ }^{[30]}$ whereas a weak ECAE texture was observed within HMRs.

Because of the lack of high-angle lamellar boundaries in plane $Z$ of sample PA, LMR fractions were especially large here (Figure 2(c)). An EBSD map, collected with a coarse step size, illustrates the extent of the large-scale heterogeneity in this plane (Figure 11). In this map, the ECD of the largest LMR is approximately $50 \mu \mathrm{m}$, which is similar to the average size of the original grains. The significant local heterogeneity observed in this plane implies that fairly large regions must be investigated in order to collect representative boundary statistics. The comparatively low fraction of HABs found in plane $Z$ in sample PA is consistent with transmission electron microscopy (TEM) results of Cabbibo, ${ }^{[31]}$ who measured more than 1000 misorientations in this plane in ECAEprocessed Al bars.

Compared to the route A sample, sample PB is less heterogeneous as indicated by the lower LMR fractions (see Figure 10). Additionally, the values for microstructural parameters such as the average subgrain size and $\mathrm{HAB}$ fraction obtained in the three different sample planes are more similar in sample PB than in sample PA.

Apparently, more uniform and isotropic microstructure refinement is achieved in sample $\mathrm{PB}$ by providing shear deformation in two orthogonal planes. Overall, this route produces slightly smaller subgrains than route A, which results in a higher hardness for sample PB compared with sample PA (Figure 7).

The results obtained in the present experiment on sample PB can be compared with the TEM data of Kamachi et al. ${ }^{[8]}$ for a thin $(5 \mathrm{~mm})$ Al plate deformed by four passes. As expected, due to the lower strain imposed in their study, the subgrain size was larger $(\sim 0.9 \mu \mathrm{m})$ in the four-pass sample than in our material. However, in contrast to our observations, the subgrain sizes measured in the three orthogonal planes of their sample were reported to be similar. ${ }^{[8]}$ The microstructural heterogeneity was analyzed in Reference 8 by considering morphological features of deformation structures, i.e., by distinguishing between regions with either equiaxed or elongated structures. From the analysis of selected area diffraction patterns, it was concluded that regions with the elongated structures contained mostly LABs.

In our PB sample, subgrains were, in general, not equiaxed, as can be seen from Figure 3 and from the data in Figure 6. Therefore, a distinction between different regions based solely on morphological characteristics does not give an adequate description of the heterogeneity of the deformed microstructure. Instead, the current work uses a more rigorous and universal description of heterogeneity in microstructural refinement based on the data in orientation maps. Although the reason for the difference in subgrain shape between the four-pass sample described in Reference 8 and our material is not very clear, it can be suggested that some differences in the microstructure development could, for 
example, be due to different friction conditions in the solid die used by Kamachi et al. ${ }^{[8]}$ and in the die with a sliding floor applied in our experiment. It is expected that the microstructure development in the body of thin ECAE plates could be particularly sensitive to surface friction. Further analysis is required to understand the influence of the die design, friction conditions, and sample thickness on microstructural evolution during multipass ECAE of plates.

\section{B. Comparison with Bar Samples}

For bar and rod samples, ECAE processing via route $\mathrm{Bc}$ has been considered by many authors to be the optimum deformation route, most rapidly creating an array of equiaxed grains separated by HABs. ${ }^{[3]}$ An opposing view has been presented by Gholinia et al. ${ }^{[25]}$ and Berta et al., ${ }^{[27]}$ who concluded that route $\mathrm{A}$ was most effective for producing the greatest fraction of HABs. Route A was reported to be more effective than route $\mathrm{Bc}$ also in terms of achieving a uniform microstructure. There have been several attempts (reviewed in Reference 3) to explain this contradiction, mostly drawing attention to the fact that the different conclusions were originally made after studying samples extruded through ECAE dies with either 90 or $120 \mathrm{deg}$ angles between channels. However, a number of studies of boundary misorientations in samples processed using $90 \mathrm{deg}$ dies $^{[18,20,28,32]}$ produced results consistent with the findings presented after ECAE with $120 \mathrm{deg}$ dies. ${ }^{[25,27]}$

The quantitative data obtained in the current experiment from three orthogonal planes provide additional arguments to the debate regarding the efficiency of the different routes for microstructure refinement. Considering that the microstructure and hardness in the center of the route A samples were not appreciably sensitive to the sample shape (Section II), statistical data from the $\mathrm{PA}$ and $\mathrm{Bc}$ samples can be used to rationalize the contradictory conclusions on the effectiveness of routes $\mathrm{A}$ and $\mathrm{Bc}$ obtained in previous studies of bar and rod samples. First, we note that in agreement with many previous publications, the fraction of HABs in planes $X$ and $Y$ was higher in the route A sample than in sample $\mathrm{Bc}$. Higher fractions of HABs recorded in these planes after route A ECAE were the basis for a general conclusion that route $\mathrm{A}$ was more efficient for refining the microstructure by increasing the area of HABs. However, as follows from the results of the current investigation, this general conclusion does not reflect the fact that the microstructure and boundary populations in plane $Z$ of the route A sample are significantly different from those observed in planes $X$ and $Y$.

The effect of the inspection plane can further be demonstrated by extracting the total length of HAB traces per unit area $L_{\mathrm{A}}^{\mathrm{EBSD}}$ directly from EBSD maps. It should be noted that due to the square grid used for collecting the data, inclined boundary traces in the EBSD maps are represented by a series of steps, which results in an overestimation of the total length. A correction $L_{\mathrm{A}}=\pi / 4 \quad L_{\mathrm{A}}^{\mathrm{EBSD}}$ was therefore applied assuming for simplicity an equal likelihood of all

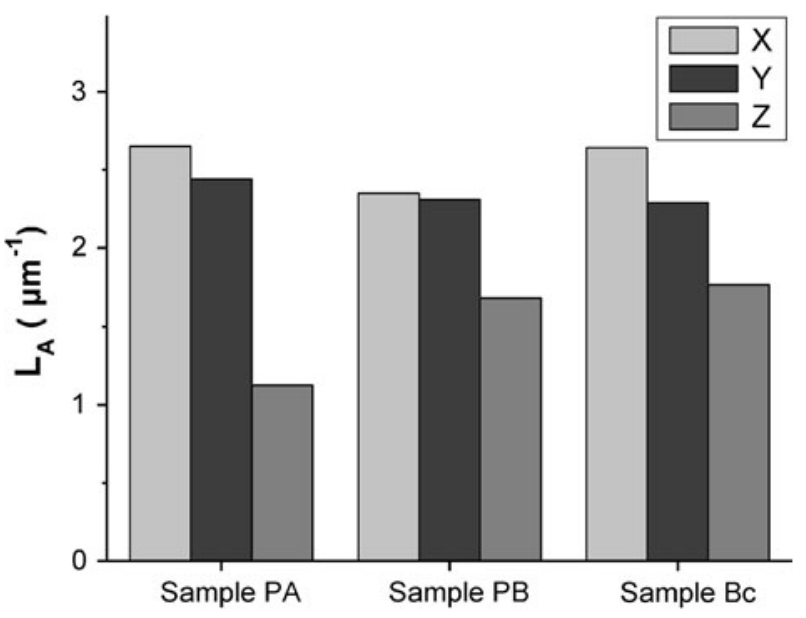

Fig. 12-Estimated lengths of HAB traces per unit area $\left(L_{\mathrm{A}}\right)$.

boundary inclinations. ${ }^{[33]}$ Since this assumption does not take into account the different shape of subgrains in the different planes, values in Figure 12 should be considered to be a rough estimate of true $L_{\mathrm{A}}$ values. Despite this, Figure 12 well represents the principal differences in the different planes, i.e., for each sample, the refinement by HABs in plane $Z$ was less pronounced than in planes $X$ and $Y$. As seen in Figure 12, the smallest $L_{\mathrm{A}}$ value was obtained in plane $Z$ of sample PA, which indicates that in this sample plane $Z$ contained fewer HABs than in any other sample. Note that in contrast to the HAB fraction, $L_{\mathrm{A}}$ is not biased by the limited angular resolution of the EBSD technique. It is thus a more convenient parameter for characterizing the refinement by HABs than the fraction of these boundaries calculated from EBSD maps.

Comparing the samples studied in the current work, the microstructure of sample $\mathrm{Bc}$ appears most homogeneous and refined, especially in plane $X$. The greater refinement and the lowest LMR fraction observed in the $X$ plane of sample Bc may be due to a large variety of angles at which shear planes intersect this plane during multipass route $\mathrm{Bc}$ deformation. ${ }^{[34]}$ The considerable difference in the extent of refinement of the Bc and PA samples explains the difference in their hardness (Figure 7). The mean hardness of the route $\mathrm{Bc}$ sample is also higher than that of sample PB, although in this case, the difference is not statistically significant (Figure 7). Considering that plate PB was only slightly less homogeneous than sample Bc and taking into account technological advantages of plates over bar and rod samples, thick plates produced with 90 deg sequential rotations appear to be well suited for industrial processing.

The result that route $\mathrm{Bc}$ is able to produce a comparatively homogeneous and well-refined microstructure is in agreement with several previous reports. ${ }^{[28,34,35]}$ Despite this general agreement, it does not seem reasonable to suggest that there is a simple universal rule determining which ECAE route is more effective in terms of microstructure refinement by HABs, since differing results have also been reported in the literature (summarized in References 20 and 32). Comparing results of the present experiment with those 
obtained for a similar initial material deformed using a different die, ${ }^{[20]}$ it is evident that sample Bc studied in our work was refined much more homogeneously than a route $\mathrm{Bc}$ sample investigated in a previous study. ${ }^{[20]}$ Note that the material described in Reference 20 experienced a significant expansion of the shear plane due to the formation a large dead metal zone at the die corner, which is indicative of substantial friction during processing. In contrast, in the current experiment, the samples were extruded using a die with a sliding floor, which effectively reduces friction and enables deformation conditions more closely approaching those of simple shear. ${ }^{[6,9]}$

It is significant that also mechanical tests do not always produce consistent data when different routes are compared. For example, in several studies, ${ }^{[36,37]}$ the tensile strength of route $\mathrm{Bc}$ samples tested along the ED was found to be higher than that for route A samples after identical numbers of passes. However, other authors reported higher tensile strengths in route A samples compared to samples extruded via route Bc. $^{[32,38]}$ Moreover, in a number of studies, no considerable differences between the strength of route $\mathrm{A}$ and route $\mathrm{Bc}$ samples were reported. ${ }^{[39,40]}$ It is therefore suggested that the material flow during ECAE and, hence, microstructure and mechanical properties not only depend on the nominal parameters describing the ECAE route and elementary die geometry but also may be dependent on the specific die design and actual friction conditions.

\section{CONCLUSIONS}

The microstructure in the center of 15 -mm-thick aluminum plates heavily deformed using ECAE either with no rotation (sample PA) or with 90 deg sequential rotations about the plate normal (sample $\mathrm{PB}$ ) has been characterized quantitatively in three orthogonal planes. A comparison has been made between the microstructures of these two plates and bars processed either via route $\mathrm{A}$ or via route $\mathrm{Bc}$ with a 90 deg rotation about the longitudinal axis. The following conclusions can be drawn from this experimental study.

1. For planes $X$ and $Y$ containing the normal direction of the plate, the fraction of HABs was slightly higher in sample PA than in sample PB, where the $\mathrm{HAB}$ fraction was about 70 pct in all planes inspected. Even though HAB fractions in the different planes of sample $\mathrm{PB}$ were similar, the total length of $\mathrm{HAB}$ traces per unit area in this sample was considerably smaller in plane $Z$ than in the two other inspected planes. Because of the lack of high-angle lamellar boundaries in plane $Z$ of sample PA, both the fraction of HABs and the total length of HAB traces per unit area in this plane were significantly smaller than those in the other two inspected planes.

2. An analysis of the microstructure of the plate samples revealed that average subgrain sizes in planes $X$ and $Y$ were similar, $\sim 0.5 \mu \mathrm{m}$. The average subgrain size was, however, larger in plane $Z$, where it was found to be $\sim 0.8 \mu \mathrm{m}$ and $0.7 \mu \mathrm{m}$ in samples PA and $\mathrm{PB}$, respectively. Hardness measurements along the center line of the plates indicated that sample PA was slightly softer than sample PB.

3. The microstructure of sample PA was more heterogeneous than that of sample PB as evident from the greater LMR fractions observed in each plane of sample PA. In planes $X$ and $Y$ of this sample, heterogeneities were observed in the form of bands containing similar crystallographic orientations. In plane $Z$ of sample PA, the size of the largest LMR was comparable to the original average grain size.

4. Comparing the plate and bar samples inspected in this work, the microstructure of the bar Bc sample produced with 90 deg rotations about the longitudinal axis was most refined and least heterogeneous. Significant differences in the structural parameters were observed between samples $\mathrm{Bc}$ and $\mathrm{PA}$. The differences between samples $\mathrm{PB}$ and $\mathrm{Bc}$ were less pronounced. As expected, route A produced very similar microstructures in the bar and plate samples.

\section{ACKNOWLEDGMENTS}

O.V.M. acknowledges support from the Danish National Research Foundation and the National Natural Science Foundation of China (Grant No. 50911130230) for the Danish-Chinese Center for Nanometals. Discussions with Professor A. Godfrey, Dr. J.R. Bowen, and Dr. N. Hansen are gratefully appreciated.

\section{REFERENCES}

1. R.Z. Valiev, R.K. Islamgaliev, and I.V. Alexandrov: Progr. Mater. Sci., 2000, vol. 45, pp. 103-89.

2. D.J. Alexander: JMEPEG, 2007, vol. 16, pp. 360-74.

3. R.Z. Valiev and T.G. Langdon: Progr. Mater. Sci., 2006, vol. 51, pp. 881-81.

4. V.M. Segal: Mater. Sci. Eng. A, 1995, vol. 197, pp. 157-64.

5. S. Ferrasse, V.M. Segal, S.R. Kalidindi, and F. Alford: Mater. Sci. Eng. A, 2004, vol. 368 , pp. $28-40$

6. V.M. Segal, I.J. Beyerlein, C.N. Tome, V.N. Chuvildeev, and V.I. Kopylov: Fundamentals and Engineering of Severe Plastic Deformation, Nova Science Publishers, New York, NY, 2010, pp. 47107.

7. V.M. Segal: U.S. Patent no. 5,850,755, 1998.

8. M. Kamachi, M. Furukawa, Z. Horita, and T.G. Langdon: Mater. Sci. Eng. A, 2003, vol. 361, pp. 258-66.

9. V.M. Segal: Mater. Sci. Eng. A, 2004, vol. 386, pp. 269-76.

10. V.M. Segal: Mater. Sci. Eng. A, 2008, vol. 476, pp. 178-85.

11. S. Ferrasse, V.M. Segal, F. Alford, J. Kardokus, and S. Strothers: Mater. Sci. Eng. A, 2008, vol. 493, pp. 130-40.

12. I. Nikulin, R. Kaibyshev, and T. Sakai: Mater. Sci. Eng. A, 2005, vol. 407 , pp. $62-70$.

13. F.J. Humphreys: J. Mater. Sci., 2001, vol. 36, pp. 3833-54

14. J. Hagström, O.V. Mishin, and B. Hutchinson: Scripta Mater., 2003, vol. 49, pp. 1035-40.

15. J. Hagström: Proc. Aluminium Alloys: Their Physical and Mechanical Properties (ICAA-9), J.F. Nie, A.J. Morton, and B.C. Muddle, eds., Institute of Materials Engineering Australasia Ltd., North Melbourne, Victoria, Canada, 2004, pp. 305-11. 
16. H.-E. Ekström, O.V. Mishin, L. Östensson, and J. Hagström: Mater. Sci. Forum, 2006, vols. 519-521, pp. 1591-96.

17. J. Sidor, R.H. Petrov, and L.A.I. Kestens: Mater. Sci. Eng. A, 2010, vol. 528, pp. 413-24.

18. O.V. Mishin and A. Godfrey: Metall. Mater. Trans. A, 2008, vol. 39A, pp. 2923-30

19. O.V. Mishin and J.R. Bowen: Metall. Mater. Trans. A, 2009, vol. 40A, pp. 1684-92.

20. O.V. Mishin, J.R. Bowen, and S. Lathabai: Scripta Mater., 2010, vol. 63 , pp. $20-23$.

21. A. Godfrey, O.V. Mishin, and T.B. Yu: Mater. Sci. Forum., 2012, vols. 715-716, pp. 203-10.

22. D.A. Hughes and N. Hansen: Acta Mater., 1997, vol. 45, pp. 3871-86.

23. Q. Liu, X. Huang, D.J. Lloyd, and N. Hansen: Acta Mater., 2002, vol. 50, pp. 3789-3802.

24. O.V. Mishin, D. Juul Jensen, and N. Hansen: Metall. Mater. Trans. A, 2010, vol. 41A, pp. 2936-48.

25. A. Gholinia, P.B. Prangnell, and M.V. Markushev: Acta Mater., 2000, vol. 48, pp. 1115-30.

26. P.B. Prangnell, J.R. Bowen, and P.J. Apps: Mater. Sci. Eng. A, 2004, vols. 375-377, pp. 178-85.

27. M. Berta, P.J. Apps, and P.B. Prangnell: Mater. Sci. Eng. A, 2005, vols. $410-411$, pp. 381-85.

28. P.-L. Sun, P.-W. Kao, and C.-P. Chang: Metall. Mater. Trans. A, 2004, vol. 35A, pp. 1359-68.
29. O.V. Mishin, D. Juul Jensen, and N. Hansen: Mater. Sci. Eng. A, 2003, vol. 342, pp. 320-28.

30. I.J. Beyerlein and L.S. Tóth: Progr. Mater. Sci., 2009, vol. 54, pp. $427-510$

31. M. Cabibbo: Mater. Charact., 2010, vol. 61, pp. 613-25.

32. Y.-Z. Tian, Q.-Q. Duan, H.-J. Yang, H.-F. Zou, G. Yang, S.-D. Wu, and Z.-F. Zhang: Metall. Mater. Trans. A, 2010, vol. 41A, pp. $2290-2303$.

33. W.Q. Cao, A. Godfrey, and Q. Liu: Mater. Sci. Eng. A, 2003, vol. 361, pp. 9-14.

34. M. Furukawa, Z. Horita, and T.G. Langdon: Mater. Sci. Eng. A, 2002, vol. 332, pp. 97-109.

35. S.D. Terhune, D.L. Swisher, K.-Oh-Oshi, Z. Horita, T.G. Langdon, and T.R. McNelley: Metall. Mater. Trans. A, 2002, vol. 33A, pp. 2173-84.

36. M.S. Soliman, E.A. El-Danaf, and A.A. Almajid: Mater. Sci. Eng. A, 2012, vol. 532, pp. 120-29.

37. S.R. Kumar, K. Gudimetla, P. Venkatachalam, B. Ravisankar, and K. Jayasankar: Mater. Sci. Eng. A, 2012, vol. 533, pp. 50-54.

38. J. May, H.W. Höppel, and M. Göken: Mater. Sci. Forum, 2006, vols. 503-504, pp. 781-86.

39. Z. Horita, T. Fujinami, and T.G. Langdon: Mater. Sci. Eng. A, 2001, vol. 318 , pp. $34-41$.

40. S. Ferrasse, V.M. Segal, K.T. Hartwig, and R.E. Goforth: Metall. Mater. Trans. A, 1997, vol. 28A, pp. 1047-57. 